\section{Percepción social de la inseguridad y apropiación simbólica del espacio en la periferia de la metrópolis de México}

\author{
Oscar Adán Castillo Oropeza \\ ORCID: http://orcid.org/0000-0002-3054-799 \\ Universidad Intercultural del Estado de Hidalgo, Hidalgo, México. \\ Correo electrónico: oscaradan68@gmail.com
}

\section{Social perception of insecurity and symbolic appropriation of space in the periphery of metropolis of Mexico}

\author{
Ángel García Morales \\ ORCID: https://orcid.org/0000-0002-8592-6843 \\ Universidad Autónoma del Estado de México, Centro Universitario Zumpango, México
}

\begin{abstract}
Resumen
En este artículo se analiza cómo la percepción social de la inseguridad y la apropiación simbólica del espacio son procesos interrelacionados en la experiencia cotidiana de los sujetos, a partir de un estudio de caso en el Fraccionamiento Villas de la Laguna, Zumpango de Ocampo, en la periferia de la metrópolis de México. En la primera parte, se definen los conceptos de percepción social de la inseguridad y apropiación simbólica del espacio. Posteriormente, se discute sobre las causas de fondo del proceso de urbanización en ese lugar, sus particularidades y consecuencias, como es la presencia de la inseguridad y sus efectos subjetivos en los habitantes. La principal conclusión es que los sujetos que habitan ese lugar lo definen como inseguro y peligroso, por medio del uso de diferentes dispositivos como el cuerpo y los sentidos, los cuales se encuentran ligados con sus diversas formas de vivir el espacio a través de los rumores y el caminar. Finalmente, para dar cuenta de ello, se implementó una estrategia metodológica que consistió en observaciones de campo, entrevistas semiestructuradas a informantes clave, recuperación de datos estadísticos oficiales, revisión de notas de periódico, fotografías y sistemas de información geográfica, con la finalidad de aportar otros elementos para la reflexión, el debate y la toma de decisiones.
\end{abstract}

\section{Palabras clave}

Apropiación simbólica del espacio; Fraccionamiento Villas de la Laguna; metrópolis de México; percepción social de la inseguridad; periferia

\begin{abstract}
This article analyzes how the social perception of insecurity, and the symbolic appropriation of space are interrelated processes in the daily experience of the subjects, based on a case study in the Villas de la Laguna neighborhood, Zumpango de Ocampo, in the periphery of metropolis of Mexico. In the first part, are defined the concepts of social perception of insecurity and symbolic appropriation of space. Subsequently, are discussed the underlying causes of the urbanization process in that place, its peculiarities, and consequences, such as the presence of insecurity and its subjective effects on the inhabitants. The main conclusion is that the subjects that inhabit that place define it as unsafe and dangerous, through the use of different devices such as the body and the senses, which are linked to their different ways of living the space through rumors and walking. Finally, to account for this, a methodological strategy was implemented that consisted of field observations, semistructured interviews with key informants, recovery of official statistical data, review of newspaper notes, photographs and geographic information systems, in order to provide other elements for reflection, debate and decision making.
\end{abstract}

\section{Keywords}

Neighborhood Villas de la Laguna; periphery metropolis of Mexico; social perception of the insecurity; symbolic appropriation of the space 


\section{Introducción}

A principios del siglo XXI, la violencia e inseguridad en México se convirtieron en un asunto de interés nacional e internacional, por la confluencia entre la "violencia de siempre" (violencia contra las mujeres, niños, etc.) y la "violencia de hoy", provocada particularmente por el combate al crimen organizado, el asesinato de activistas, entre otros (Azaola, 2012).

Según varios autores (Mainhold, 2011 Maya Solís, 2009; Moloeznik y Suárez de Garay 2012; Montero, 2012; Pasters y Castillo Berthier, 2007), México sufre actualmente una severa crisis en materia de seguridad ciudadana, la cual se ha intensificado con la militarización de la seguridad pública y la disputa entre los cárteles de la droga por el control del territorio.

De acuerdo con el Sistema Nacional de Seguridad Pública (Secretaría de Gobernación y Secretariado Ejecutivo del Sistema Nacional de Seguridad Pública [SNSP], 2017), entre 1997 y 2017 se registró un total de 334 mil 48 homicidios dolosos a nivel nacional, pero tan solo en un lapso de 10 años, de 2007 a 2017, se registraron 189 mil 863 homicidios de ese tipo que equivalen al 56,84\%. Asimismo, según la Encuesta Nacional de Victimización y Percepción sobre Seguridad Pública (ENVIPE, 2018), en 2017 la tasa nacional de victimización fue de 29 mil 746 víctimas de algún delito por cada cien mil habitantes.

Ante tal escenario, la Comisión Interamericana de Derechos Humanos (CIDH) (2015) y Amnistía Internacional (AI) (2016) coinciden que en México se atraviesa una de las peores crisis en derechos humanos. Las desapariciones forzadas, las ejecuciones extrajudiciales, la tortura, los feminicidios, el asesinato a periodistas y migrantes son parte del contexto cotidiano que los medios de comunicación reproducen y venden a las audiencias.

En México uno de los lugares donde hay mayor ocurrencia de delitos y víctimas, es la Zona Metropolitana del Valle de México (ZMVM) ${ }^{1}$. Ahí, el 82,4\% de la población percibe que hay inseguridad en su municipio o alcaldía y el 70\% considera que es uno de los problemas más preocupantes. En el estado de México, la tasa de víctimas de algún delito por cada 100 mil habitantes es de 48 mil 150, mientras que en la Ciudad de México es de 42 mil 85 víctimas por cada 100 mil habitantes (ENVIPE, 2018).

La incidencia delictiva y la percepción social de la inseguridad son síntomas, entre otras cosas, de la inestabilidad del orden institucional impuesto desde el Estado y la presencia de organizaciones criminales. Los vínculos sociales se fracturan, se genera el miedo y la estigmatización hacia el otro(s), lo cual influye en las formas de construir y socializar en el espacio urbano (Carrión, 2008; Valenzuela-Aguilera, 2016; Wacquant, 2004).

En ese sentido, varios autores (Arriaga Luco y Morales Lazo, 2006; Blakely \& Snyder, 1997; Breetzke, 2014; Caldeira, 2007; Capron, 2016, 2019; Capron y Esquivel Hernández, 2016; Chase, 2008; Davis, 2007; Enríquez Acosta, 2007; Giglia, 2003; González Luna, 2013; Guerrien, 2004; Gutiérrez Lozano, 2008; Sanín Naranjo, 2012; Zamorano, 2019a, 2019b) desde diferentes enfoques problematizan de manera general la relación entre espacio urbano e inseguridad, tanto en las ciudades del Norte como del Sur global. Son varios los temas que discuten, el miedo en los espacios públicos urbanos, los procesos de guetización ligados con el crimen y a la violencia urbana, los servicios de seguridad en las gated communities o urbanizaciones cerradas y las dinámicas de autoproducción de la seguridad en la ciudad.

Ahora bien, para el caso de la metrópolis de México, los estudios que existen al respecto tratan sobre la percepción de la inseguridad y el miedo en diferentes espacios públicos (calles, centros históricos, transporte y plazas públicas), la contratación de servicios de seguridad en zonas de gated communities (Capron, 2016; Capron y Sánchez, 2015; Céline y Capron, 2010) y, recientemente, hay un interés por analizar, en contextos inseguros, las

1 Según el Instituto Nacional de Geografía y Estadística (INEGI, 2010), la ZMVM o metrópolis de México es una de las urbes más grandes del mundo y, en 2010, concentraba un total de 22 millones de habitantes. 
representaciones sociales entre los habitantes de colonias de diferente estrato socioeconómico, al igual que la coproducción de la seguridad entre agentes públicos y privados en algunas zonas urbanas (Capron y Esquivel Hernández, 2016; Zamorano, 2019a, 2019b; Zamorano \& Capron, 2013).

Aunque estos trabajos son aportes significativos para comprender la relación entre espacio urbano e inseguridad en la ZMVM, las unidades de estudio preponderantes en dichas investigaciones son los espacios construidos para las clases medias-altas y muy poco - casi nada- se problematizan aquellos fraccionamientos urbanos de reciente creación destinados para las clases populares en la periferia metropolitana.

En este artículo la pregunta central es: ¿Cómo se presenta la percepción social de la inseguridad y la apropiación simbólica del espacio en el Fraccionamiento Villas de la Laguna, en el municipio de Zumpango de Ocampo (en adelante Zumpango por economía de palabras), el cual se ubica en la periferia de la metrópolis de México? En un primer momento se definen los conceptos de percepción social de la inseguridad, el rumor y el caminar en relación con la apropiación simbólica del espacio. Después se explica cómo se presenta el proceso de urbanización en ese lugar y sus consecuencias, en específico la presencia de la inseguridad. Para ello, se hace uso de observaciones de campo, entrevistas semiestructuradas a informantes clave, datos estadísticos oficiales, fotografías, notas de periódico y sistemas de información geográfica. Todo ello, con la intención de proponer otras herramientas teórico-metodológicas para el estudio de la inseguridad desde los sujetos que habitan la periferia urbana, que escapan a los análisis hasta ahora publicados.

\section{Percepción social de la inseguridad}

En los estudios urbanos la discusión acerca de la inseguridad, la violencia o el miedo y las narrativas sobre el crimen demandan el uso e intersección de diferentes conceptos de la mano con las experiencias de los sujetos (Laverentz, 2012). De tal forma que varios autores sugieren, en nuestro caso, ahondar en los aspectos sociales y subjetivos de la inseguridad urbana, por ello reflexionan sobre las representaciones sociales del crimen, las actitudes punitivas, la percepción y vulnerabilidad al delito, el sentimiento de inseguridad en espacios urbanos, las estrategias de autoseguridad de los individuos y el impacto de las percepciones en la elaboración de políticas públicas (Aliman \& Killias, 1992; Bergman y Kessler, 2008; Capron y Sánchez, 2015 Dammert y Bailey, 2005; Garoscio, 2006; Jasso López, 2013).

Sin embargo, a pesar de que estas investigaciones aportan elementos para problematizar la inseguridad en distintas ciudades del mundo, poco se profundiza en qué es lo social de la percepción o a qué se refiere la dimensión subjetiva de la inseguridad. En la mayoría de los casos, la percepción se reduce a las simples opiniones de los sujetos sobre la inseguridad, el crimen o la violencia. En otros, se aplican conceptos preestablecidos para analizar dicha situación como: "representación social" o "vulnerabilidad".

Por lo tanto, parece necesario definir cuáles son y cómo operan dichos componentes de la percepción de la inseguridad, para comprender esta realidad que permea la vida cotidiana de aquellos que habitan las ciudades, en concreto, las periferias urbanas pobres, como el Fraccionamiento Villas de la Laguna. Entonces, ¿qué es la percepción? y ¿cómo se percibe? Veámoslo en detalle.

La percepción tiene que ver con las formas en cómo los seres humanos abstraen, conocen y aprehenden el mundo mediante la conciencia (Husserl, 1962), la cual es determinante en la construcción subjetiva de la realidad. Ahora bien, percibir no solo implica abstraer, sino también sentir con el cuerpo (Le Breton, 2002), el motor que posibilita a los sujetos generar significaciones individuales y colectivas, desde y en diferentes lugares (Merleua-Ponty, 1994).

El cuerpo está compuesto, entre otras cosas, de sentidos (vista, oído, olfato, tacto y gusto) que no solo cumplen distintas funciones fisiológicas (mirar, escuchar, oler, tocar y saborear), de igual modo hacen posible las interacciones sociales, el intercambio de miradas, 
el reconocimiento de lugares por los olores, ruidos, entre otros. Por consiguiente, los sentidos son puentes comunicantes entre la realidad objetiva y subjetiva (Simmel, 1986).

De esa manera, la percepción alude a una interconexión entre los sentidos y los significados que los sujetos construyen al tipificar o nombrar la realidad (objetos, lugares, etc.) (Schütz, 1995). El juego de tipificaciones permite la acumulación y comunicación de experiencias a través de las conversaciones cotidianas (directas e indirectas) que mantienen o modifican su realidad subjetiva y, por ende, sus acciones (Berger y Luckmann, 2008; Blumer, 1982; Garfinkel, 2006) frente a diferentes situaciones como la inseguridad en su colonia, barrio, etc.

En ese sentido, aquí se entiende que la percepción social de inseguridad es un proceso sociosubjetivo en el que los sujetos definen, desde su experiencia en el territorio, su realidad inmediata como insegura y amenazante. Para ello, hacen uso consciente e inconscientemente de diferentes dispositivos: el cuerpo, los sentidos y las tipificaciones que alimentan los lenguajes y hacen posible la interacción con sus pares y su entorno.

Esos dispositivos se encuentran entrelazados en prácticas concretas que los sujetos producen y reproducen, de acuerdo con los tiempos sociales del espacio que habitan (calle, barrio, colonia, fraccionamiento, etc.), tal es el caso de los rumores y el caminar. Por ejemplo, caminar por una calle durante la mañana, el medio día, la noche o suponer e identificar un espacio como inseguro, depende de cómo los sujetos perciban ese lugar a raíz de la influencia de los rumores escuchados y de las violencias vividas e imaginadas que transcurren cotidianamente.

\section{Apropiación simbólica de los espacios inseguros: entre el rumor y el caminar}

El rumor en esencia se refiere a los intercambios lingüísticos sobre un suceso entre dos o más sujetos, implica la interacción cara a cara e involucra movimientos corporales, miradas y gesticulaciones (Zires, 1995). Para Zires, el rumor es "un relato vocal que atraviesa diferentes grupos sociales y contextos culturales, convirtiéndose en una polifonía de voces o concierto que se ve entretejido con los diferentes tonos, volúmenes, gestos y maneras de hablar de todos los sujetos involucrados" (1994, p. 25).

Además, los sujetos difunden el rumor por varios lugares y en distintos tiempos (Reumaux, 2009). Para Isaac Joseph el rumor está compuesto de mensajes detallados sobre la realidad, los cuales son aceptados o rechazados por los sujetos que lo repiten y transmiten a otros de forma casi mecánica (Joseph, 1988).

El rumor es una forma simultánea de informarse y comunicarse entre los sujetos (Fernández Poncela, 2012; Rouquette, 2006). Es una invención social y colectiva que trata sobre el flujo de significados que son compartidos, a partir de sus experiencias vividas o no. Por lo cual, la confluencia de los rumores es "una operación producida por el solapamiento de las interacciones" (Garfinkel, 2006, p. 41) sociales en distintos espacios tanto públicos como privados (calle, casa, supermercado, centro comercial, etc.).

No obstante, los rumores son apropiados de manera individual, después los sujetos crean o recrean los relatos que funcionan como el principal canal para su difusión. Según Michel De Certeau (2000), los relatos son el medio inmediato para acercar a los otros a diferentes realidades: escuchadas, inventadas, vividas, individuales o colectivas, con familiares, vecinos, etc. Así también en los rumores se hace referencia espacialmente a lo memorable, a lo escuchado o sucedido: "aquí o allá me sucedió", "dicen que allá roban", "el otro día me robaron mis pertenencias en ese lugar", entre otros.

Los rumores en la vida cotidiana originan que los espacios adquieran sentido para los sujetos, no solo por su composición material o física, sino también sociocultural y simbólica, incluso influyen en sus prácticas socioespaciales diarias, como caminar. De ese modo, al caminar los espacios se nombran, se sienten e identifican, en este caso, como lugares inseguros, violentos y peligrosos. 
Por ello, los sujetos aprehenden a caminar en el territorio, su capacidad de actuar y de formar rutinas cambia en la medida de su necesidad de protección y adaptación al contexto de inseguridad que perciben. Según JeanFrançois Augoyard (1979), la práctica de caminar es un acto que involucra el uso de los sentidos, piezas clave para el entendimiento sensorial y emotivo del espacio. Para Le Breton, caminar es un:

Método de inmersión en el mundo, un medio para dejarse penetrar por la naturaleza, para ponerse en contacto con un universo inaccesible a las formas de conocimiento o de percepción de la vida cotidiana. Durante la marcha, el caminante amplía su mirada sobre el mundo, sumerge su cuerpo en nuevas atmósferas (2011, p. 34).

De ahí que, cuando los sujetos caminan, el cuerpo funciona como una herramienta que les permite reconocer, experimentar y apropiarse simbólicamente de su espacio cotidiano (Lefebvre, 2013; Wacquant, 2006), así como de otros espacios próximos a su lugar de residencia (Duhau y Giglia, 2004; Guérin-Pace, 2003), aquellos lugares que por medio de los rumores y el caminar resultan significativos, entre otras cosas, por las historias de miedo e inseguridad que los rodean.

La percepción social de la inseguridad se ancla en los rumores que se transmiten, impulsan y modifican las prácticas de caminar y experimentar el espacio a una escala de a pie. El encuentro cotidiano de los sujetos con los rumores y su acercamiento o residencia en espacios conocidos como inseguros y poco habitables es un acto socioespacial paralelo que da sentido a su propia existencia.

\section{Metodología}

En los estudios sobre inseguridad urbana, predominan al menos dos perspectivas de análisis. La primera es aquella desarrollada primordialmente por los Estados nacionales, las agencias o consultorías privadas y algunas comunidades científicas afines que implementan una serie de métodos estadísticos para medir, evaluar y proyectar, dado sea el caso, el impacto, crecimiento o decremento de actividades delictivas en determinadas áreas geográficas a diferentes escalas (local, regional o nacional) (Gondra Bustinza, 2008).

En estas investigaciones, las herramientas metodológicas que más se utilizan son las encuestas y los sondeos, pero ambos no permiten profundizar en las opiniones de los individuos, es decir, en el cómo, cuándo y dónde, por lo que se desconocen los elementos subjetivos y situacionales del fenómeno. Además, estos procedimientos metodológicos invisibilizan el sentir y actuar de los sujetos frente a los diferentes escenarios de violencia y crimen, como en la periferia de la metrópolis de México.

En la segunda perspectiva, algunos autores resaltan la importancia de hacer investigación desde el lugar dónde los sujetos sienten y perciben la inseguridad (Barker y Crawford, 2011; Kessler, 2011, 2012, 2013; Moloeznik, 2012; Widner, Languin, Pattaroni, Kellerhals y Robert, 2004; Zauberman, Robert, Névanen y Bon, 2013). En estos análisis, las emociones, los símbolos, los significados del otro(s) y su espacio inmediato de existencia son variables fundamentales para la reflexión, a los cuales este trabajo pretende sumarse.

La estrategia metodológica que construimos se aleja de las sugerencias de algunos autores (Taylor y Bogdan, 1987), quienes cuestionan que hacer investigación en los lugares comunes al investigador provoca poca fiabilidad en los resultados por su familiaridad con la realidad. En este caso, el hecho de que el espacio donde radicamos se encuentre relativamente cerca -aproximadamente a 7 kilómetros de distancia-del Fraccionamiento Villas de la Laguna (Figura 1) y, que alguien del equipo de trabajo resida en ese lugar, representó una ventaja considerable, pues la entrada al campo y el contacto con los habitantes fue sin complicaciones y de forma paulatina, siempre acorde con sus propios ritmos, códigos y lenguajes.

En las primeras visitas de campo se realizaron observaciones y entrevistas exploratorias con algunos habitantes y personal de la policía local, todas coincidieron en que el fraccionamiento es uno de los espacios más inseguros y peligrosos del municipio de Zumpango. 
Figura 1

Ubicación Fraccionamiento Villas de la Laguna en Zumpango

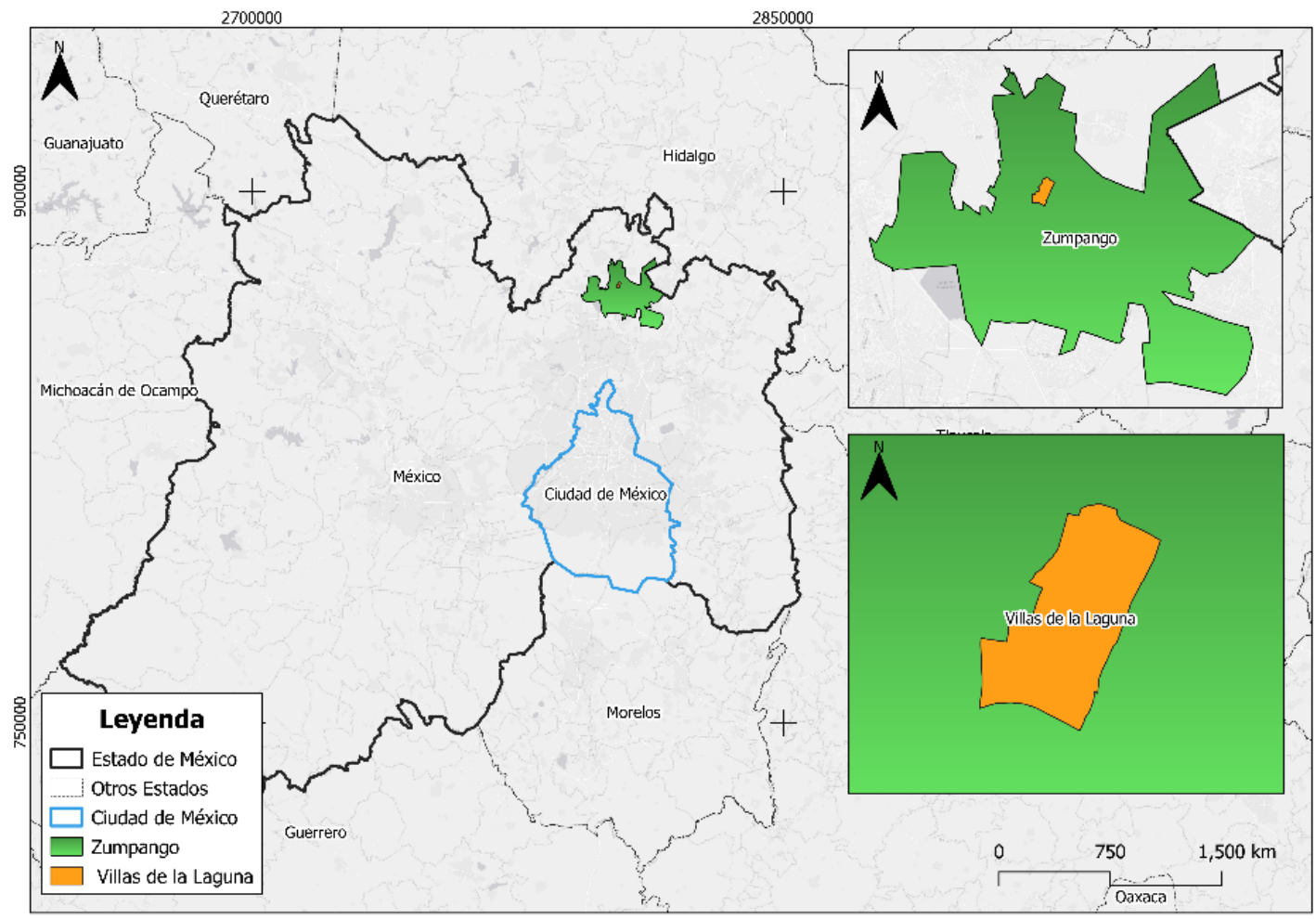

Los recorridos se hicieron entre junio de 2017 y enero de 2018. En cada visita, nuestra permanencia se prolongó más tiempo del estipulado, así fuimos adoptando una actitud de extrañeza ante la cotidianidad espacial y temporal de los que habitan ahí (Garfinkel, 2006), observar el terreno con otros ojos nos permitió obtener información, que registramos en nuestro diario campo y con la cámara fotográfica, con ello dimos cuenta de las transformaciones socioterritoriales en ese lugar y del ambiente de inseguridad imperante.

En la medida en que nos fuimos convirtiendo en etnógrafos y entrevistadores nativos (Licona Valencia, 2015; Lozano Rivera, 2012), aplicamos la técnica "bola de nieve" con la intención de identificar lo que definimos como "red de informantes clave", compuesta de diferentes sujetos (amas de casa, comerciantes, estudiantes, transportistas, entro otros). Las personas que entrevistamos viven en algunos microespacios (calles cerradas o avenidas) que se consideran peligrosos e inseguros por habitantes del mismo fraccionamiento, de otros lugares circundantes, medios de comunicación local y personal de la policía municipal, por determinadas circunstancias: venta de drogas, viviendas abandonadas, ocurrencia de robos y asesinatos.
Se realizaron 13 entrevistas semiestructuradas entre diciembre de 2017 y enero de 2018, con el objeto de comprender, desde los testimonios de los sujetos, cómo se presenta la relación entre la percepción social de la inseguridad y la apropiación simbólica del espacio. Las entrevistas se transcribieron y codificaron respectivamente.

\section{El desbordamiento geográfico de la metrópolis de México: el caso de Zumpango}

Durante el siglo XX, la dinámica demográfica de la Ciudad de México cambió abruptamente, debido al proceso de industrialización en el período de implementación del modelo de industrialización por sustitución de importaciones (ISI) (Garza, 1985), ya que dichos cambios económicos provocaron la primera gran ola migratoria interna del campo a la ciudad y, por ende, el crecimiento "natural" de la metrópolis.

Según varios autores (Aguilera Ortega y Corral Fernández, 1993; Esquivel, Flores y Ponce, 2006; Garza, 1990) la composición socioterritorial de la ZMVM se puede ubicar en cuatro períodos. De 1900 a 1930 cuando inició el poblamiento de la zona centro de la Ciudad de México. 


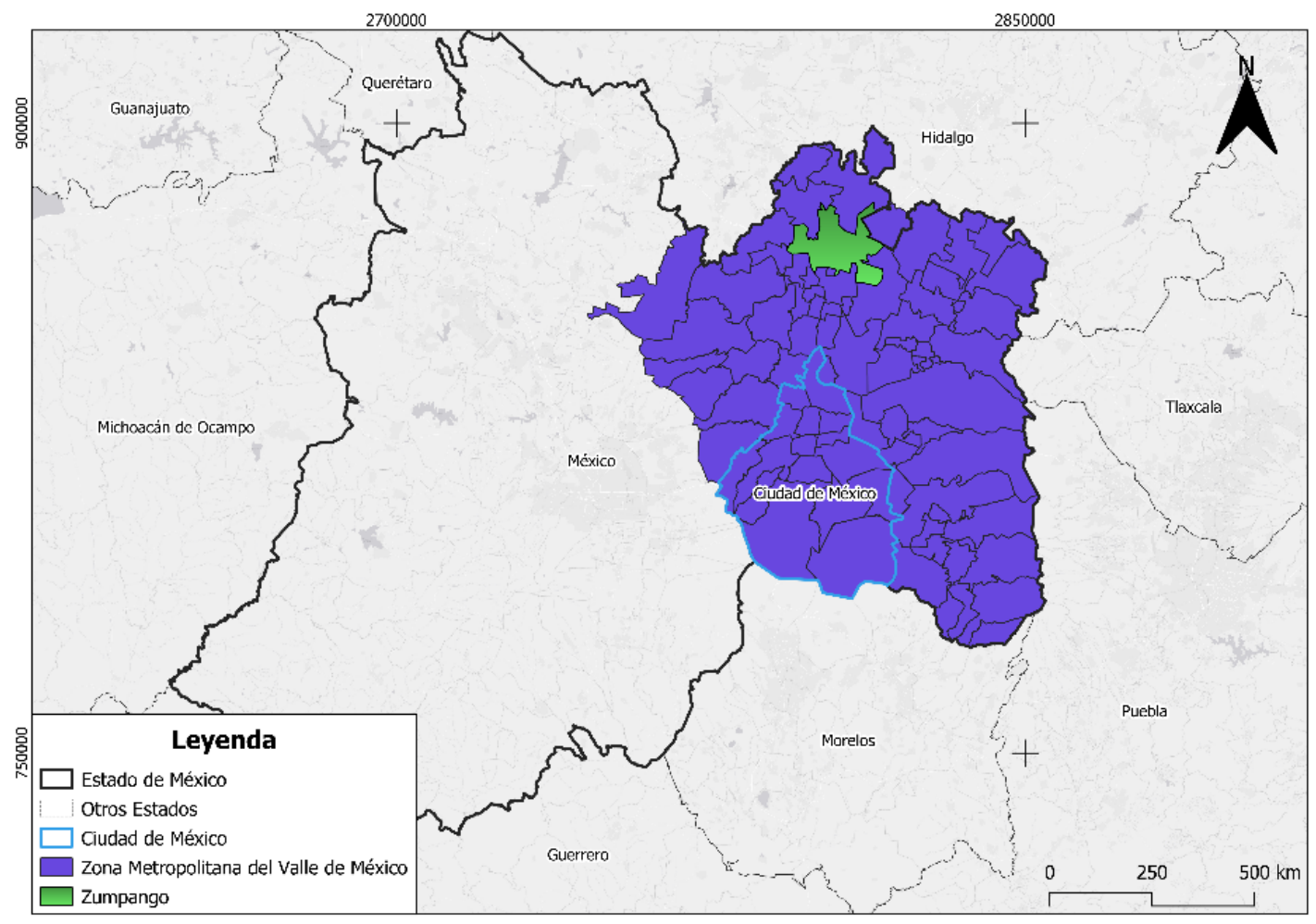

De 1930 a 1950, en esta etapa la población de la Ciudad de México aumentó a 3 millones de habitantes, muchos de ellos provenían de entidades federativas aledañas a la urbe como Hidalgo, estado de México o Puebla. De 1950-1980, el crecimiento de la ciudad se expandió hacia algunos municipios del estado de México como Tlalnepantla de Baz y Naucalpan de Juárez. En este período la población creció de 3 a 14 millones de habitantes y aumentó la demanda de suelo habitacional en otros municipios de la periferia como Ecatepec de Morelos, Nezahualcóyotl, Cuautitlán Izcalli, entre otros. Finalmente, de 1990 hasta la actualidad, este período se caracteriza porque la extensión de la mancha urbana rebasa esos municipios (Esquivel, Flores y Ponce, 2006) y ahora se expande hacia otros lugares de la metrópolis, como lo veremos enseguida.

En la actualidad la ZMVM la componen 76 unidades político-administrativas, las 16 alcaldías de la Ciudad de México, 59 municipios del estado de México y un municipio del estado de Hidalgo (Instituto Nacional de Estadística y Geografía [INEGI], 2010) (Figura 2).

Ante el desbordamiento paulatino y sin control de dicho espacio geográfico, la falta de vivienda y servicios (agua, transporte, drenaje, etc.) son necesidades recurrentes. En la primera mitad del siglo XX el Estado intentó encargarse de cubrir la demanda de vivienda y creó la Dirección de Pensiones Civiles y de Retiro, el Banco Nacional Hipotecario y de Obras Públicas, el Instituto del Fondo Nacional de la Vivienda para los Trabajadores, el Fondo de la Vivienda del Instituto de Seguridad y Servicios Sociales de los Trabajadores del Estado, el Fondo de la Vivienda Militar y el Programa Financiero de Vivienda, estas instancias gubernamentales estaban de alguna manera involucradas con la construcción y oferta de viviendas formales (García Peralta Nieto, 2016; Kenneth, 2014; Schteingart, 2001; Ward, 2004). Pero en la práctica "la mayoría de los beneficiarios de estos programas de vivienda fueron trabajadores sindicalizados o empleados públicos, y su impacto fue mínimo; en la práctica esos programas fueron incapaces de satisfacer las necesidades habitacionales de la población mexicana" (Kenneth, 2014, p. 117).

En consecuencia, en la segunda mitad del siglo XX la producción de viviendas de tipo informal incentivó la apropiación de tierras agrícolas en la periferia de la ZMVM y la creación de distintos mecánismos e instituciones 
Figura 3

Ubicación de los municipios que integran el Programa Ciudades del Bicentenario

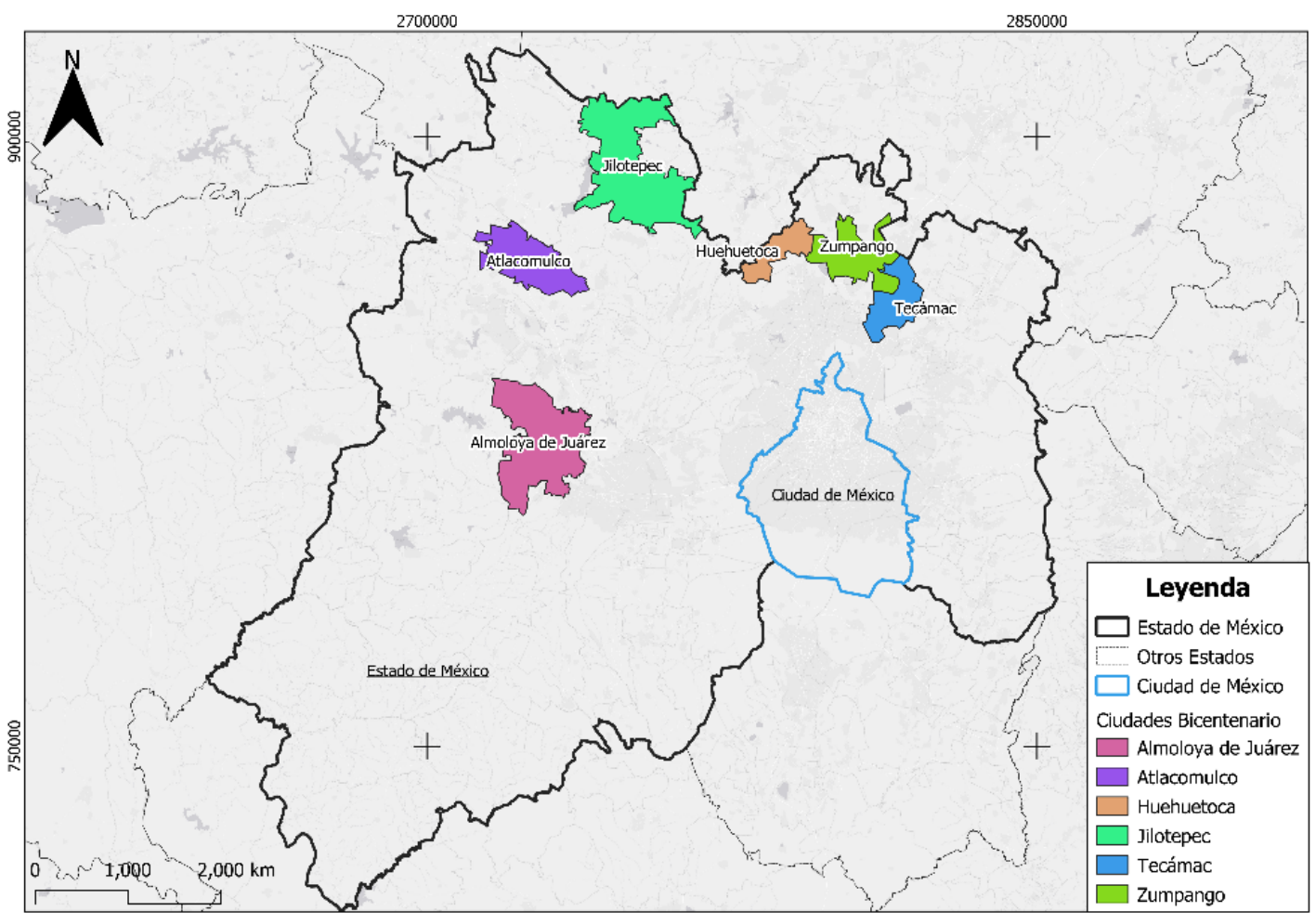

para legalizar la propiedad de las viviendas ocupadas irregularmente, como: el Reglamento de Asociaciones Pro Mejoramiento de Colonias del Distrito Federal (hoy Ciudad de México) y el Instituto de Acción Urbana e Integración Social del Estado de México (Azuela, 1990; Cruz Rodríguez, 2000).

Sin embargo, en 1990 el Estado "perdió” el monopolio de la producción de la vivienda, además la desregulación del sector de la vivienda significó la liberalización del régimen de propiedad de las tierras comunales y ejidales la transformación de aquellos organismos estatales en agentes de crédito hipotecario y la aparición de grandes grupos empresariales en el mercado de la vivienda (Coulomb Bosc, 2013; García Peralta Nieto, 2016; Imitan, Olivera y Beswick, 2016; Juárez Neri, 2003; Merchand, 2016; Pirez, 2014; Pradilla Cobos, 2016), los cuales han definido el rumbo de la urbanización periférica hacia otros municipios como Tecámac, Huehuetoca y Zumpango, a través de la construcción masiva o en serie de fraccionamientos y conjuntos urbanos destinados, en su mayoría, para las clases populares (Castillo y Alejandre, 2012).
En esta otra fase de expansión territorial de la periferia metropolitana, se ponen en marcha distintos planes de desarrollo urbano en los cuales convergen intereses público-privados, como es el caso del Programa Ciudades del Bicentenario (2007), cuyo objetivo fue planificar el desarrollo urbano integral de varios municipios: Almoloya de Juárez, Atlacomulco, Jilotepec, Huehuetoca, Tecámac y Zumpango (Figura 3) debido a la disponibilidad de suelo, recursos naturales e infraestructura (Comisión Coordinadora para el Impulso a la Competitividad del Estado de México, 2007), con la intención de potencializar una economía regional anclada en actividades industriales y de servicios, aunado a una amplia oferta de vivienda de interés social que serviría como un recurso o mecanismo para la desconcentración poblacional de algunos municipios que colindan con la Ciudad de México, tal es el caso de Ecatepec de Morelos, Chimalhuacán o Nezahualcóyotl.

En el caso de Zumpango, donde se encuentra nuestra área geográfica de estudio, el gobierno del estado de México autorizó, en el período de 2000 a 2010, la construcción de $24,56 \%$ del total de viviendas de interés social que se edificarían en los seis municipios que integran el Proyecto 
Ciudades del Bicentenario (Secretaría de Desarrollo Urbano y Metropolitano, 2017).

Para lo cual, se estimó que la superficie urbanizable de ese lugar era de 7.832 hectáreas en las que distintas empresas inmobiliarias privadas como: Geo Hogares Ideales, Proyecto Inmobiliarios de Culiacán, Casas Beta del Centro, Conjunto Parnelli, Constructora Mogue, Hermes Edificaciones, entre otras, construyeron un total de 43.585 viviendas (INEGI, 2012; Secretaría de Desarrollo Urbano y Metropolitano, 2017).

Asimismo, de acuerdo con fuentes oficiales, la población de ese municipio aumentó, de 99.774 habitantes en el año 2000 a 159.647 habitantes en el año 2010, de los cuales 35.102 residían en los fraccionamientos urbanos de reciente creación (INEGI, 2010).

A raíz del abrupto desarrollo inmobiliario de vivienda en Zumpango, aparecen una serie de problemas que no son simplemente ocasionados por el incremento de la población, sino por una serie de consecuencias en cascada como: el abandono o poca ocupación de vivienda nueva, la carencia de servicios (agua, drenaje, alcantarillado, etc.), así como de espacios públicos para la convivencia cotidiana, transporte público de calidad y la poca accesibilidad a las fuentes de trabajo (Castillo y Alejandre, 2012; Cruz-Muñoz e Isunza, 2017).

Según el Índice de las Ciudades Prósperas (ONU Hábitat, 2018), este municipio tiene un índice de prosperidad débil, eso significa que hay una carencia de políticas públicas a nivel local para atender diversos problemas relacionados con la urbanización, la falta de crecimiento económico local, sostenibilidad ambiental, gobernanza y legislación urbana, infraestructura y equipamiento urbano, entre otros.

Pero estos fraccionamientos urbanos de reciente creación son poco habitables, no solo por la falta o fortalecimiento de políticas públicas, la ocupación o abandono de las viviendas, sino por la emergencia de otros problemas relacionados con la precarización del espacio y de las condiciones de existencia de aquellos que habitan esos lugares, como lo es la violencia e inseguridad cotidiana que influye en la interacción social y las prácticas socioespaciales de los sujetos (Castillo y Alejandre, 2012).

Por ejemplo, en el año 2016 la tasa de homicidios dolosos en Zumpango fue de 21,4 homicidios por cada cien mil habitantes, superior a la tasa nacional de 18,76 homicidios dolosos. En ese mismo año, se registraron 306,59 robos de vehículos por cada cien mil habitantes, lo cual ubicó a este lugar entre los 20 municipios, de más de cien mil habitantes, con las mayores tasas de robo de vehículos (Observatorio Nacional de Seguridad, Justicia y Legalidad, 2016).

De igual manera, entre 2011 y 2017, se registraron 318 homicidios, 119 homicidios culposos o imprudenciales y 199 homicidios dolosos o intencionales. Cabe destacar que, en 2011, en 21,4\% de los homicidios dolosos se utilizaron armas de fuego y 60,87\% en 2017 (SNSP, 2018).

Ante este panorama, la inseguridad es percibida como un hecho real en sus consecuencias. En el Fraccionamiento Villas de la Laguna, los habitantes experimentan un ambiente de zozobra y miedo, ante la acción despreocupada de las autoridades locales para atender las demandas de vigilancia, monitoreo y control de la delincuencia. Al respecto Antonio González, director general de Desarrollos Inmobiliarios Laguna (empresa de comercio de viviendas recuperadas que tiene sus oficinas principales en el Fraccionamiento Villas de la Laguna), afirmó a la prensa nacional lo siguiente:

Nosotros tenemos operando aquí cerca de 4 años y en los últimos 2 años se ha incrementado muchísimo el problema de los asaltos. La gente de ahí (Fraccionamiento Villas de la Laguna) desgraciadamente está acostumbrada a que los asalten, porque si no es en la combi (transporte público local) es cuando van caminando (...). Desgraciadamente existen demasiadas viviendas que están invadidas y eso ha generado mucha delincuencia (Hernández, 2018, p. 4). 

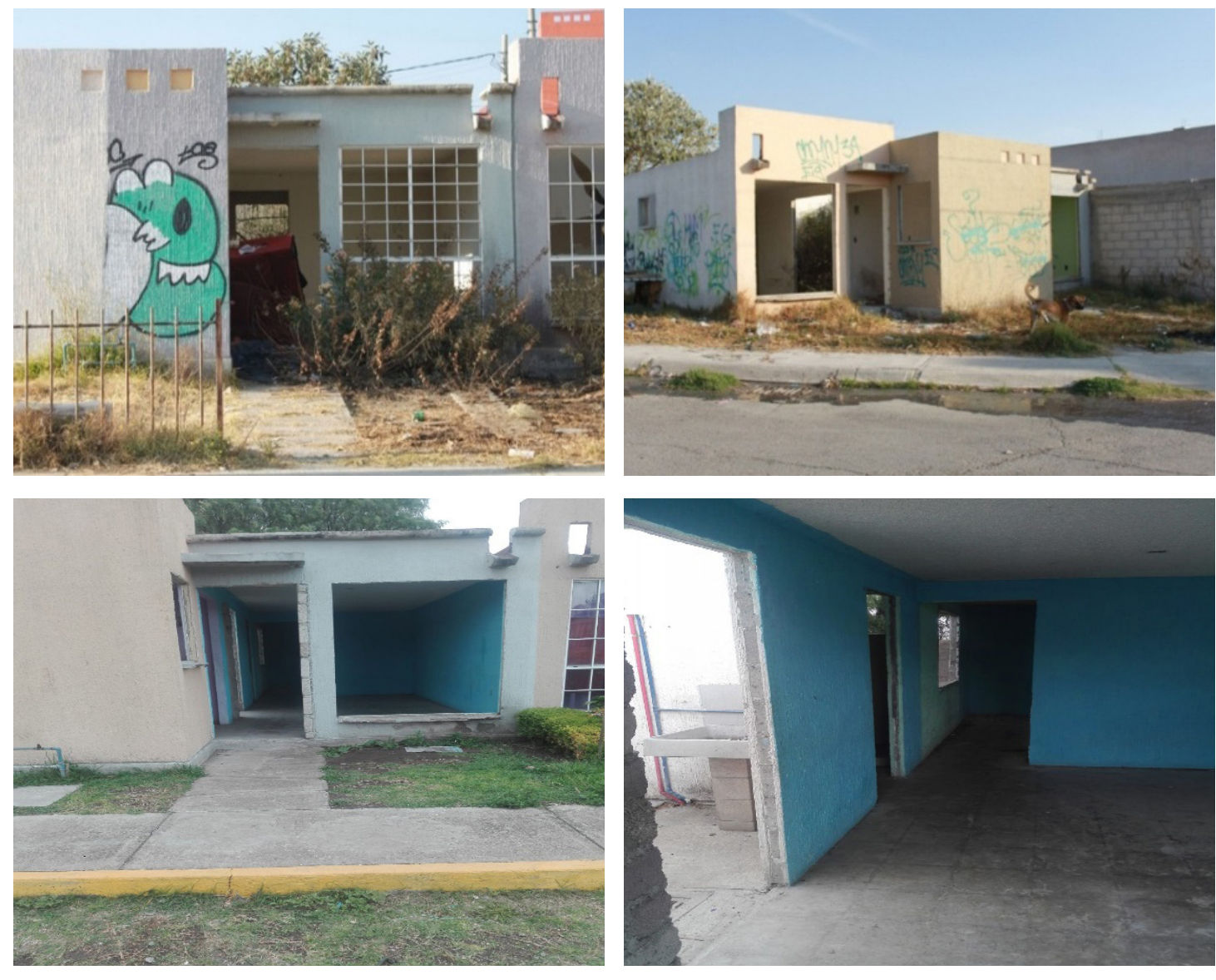

En su mayoría, los habitantes de ese lugar, principalmente hombres jóvenes y adultos, se trasladan a la Ciudad de México desde muy temprano a trabajar y llegan por la tarde-noche. Las mujeres, adultos mayores, infantes y adolescentes son los que pasan la mayor parte del tiempo en los hogares, cuyo espacio parece a simple vista reducido.

En la opinión de algunos sujetos, el fraccionamiento se ha deteriorado al paso de los años, especialmente por el problema de la inseguridad. Una joven explica lo siguiente:

Era todo muy tranquilo (...) había mucha limpieza, casi no había contaminación y había mucha seguridad. Hay mucha delincuencia, la policía casi no entra por aquí (...) si ven que están robando aquí, no hacen nada. Por aquí hay mucha delincuencia, mucha inseguridad. Antes aquí no había inseguridad, ahora sí (B. López, entrevista semiestructurada, 13 de diciembre de 2017).
Algunas de las viviendas, no solo se encuentran abandonadas, sino saqueadas. El robo a casa habitación es recurrente, los delincuentes aprovechan cuando los dueños de los inmuebles no se encuentran, de algunas casas solo han dejado las paredes, se llevan incluso la protección de puertas y ventanas (Figura 4). Juan Jacobo habitante de ese fraccionamiento comenta:

Lo que más nos roban son los tanques de gas y boilers. La semana pasada llegué a casa en la noche. Cuando ingresé noté algo raro, pero no le di importancia. $\mathrm{Al}$ abrir la puerta del baño ya no había regadera, inodoro, ni lavabo. También me robaron el calentador de agua con todos sus accesorios (Arellano, 2014, p. 2).

En otras residencias hay mantas colgadas en las paredes, en las que se expresa la inconformidad de la población por la atmósfera de delincuencia que se vive en ese lugar. Es una acción de advertencia para los delincuentes, pero más allá, es una estrategia geosimbólica (Giménez, 1999) 

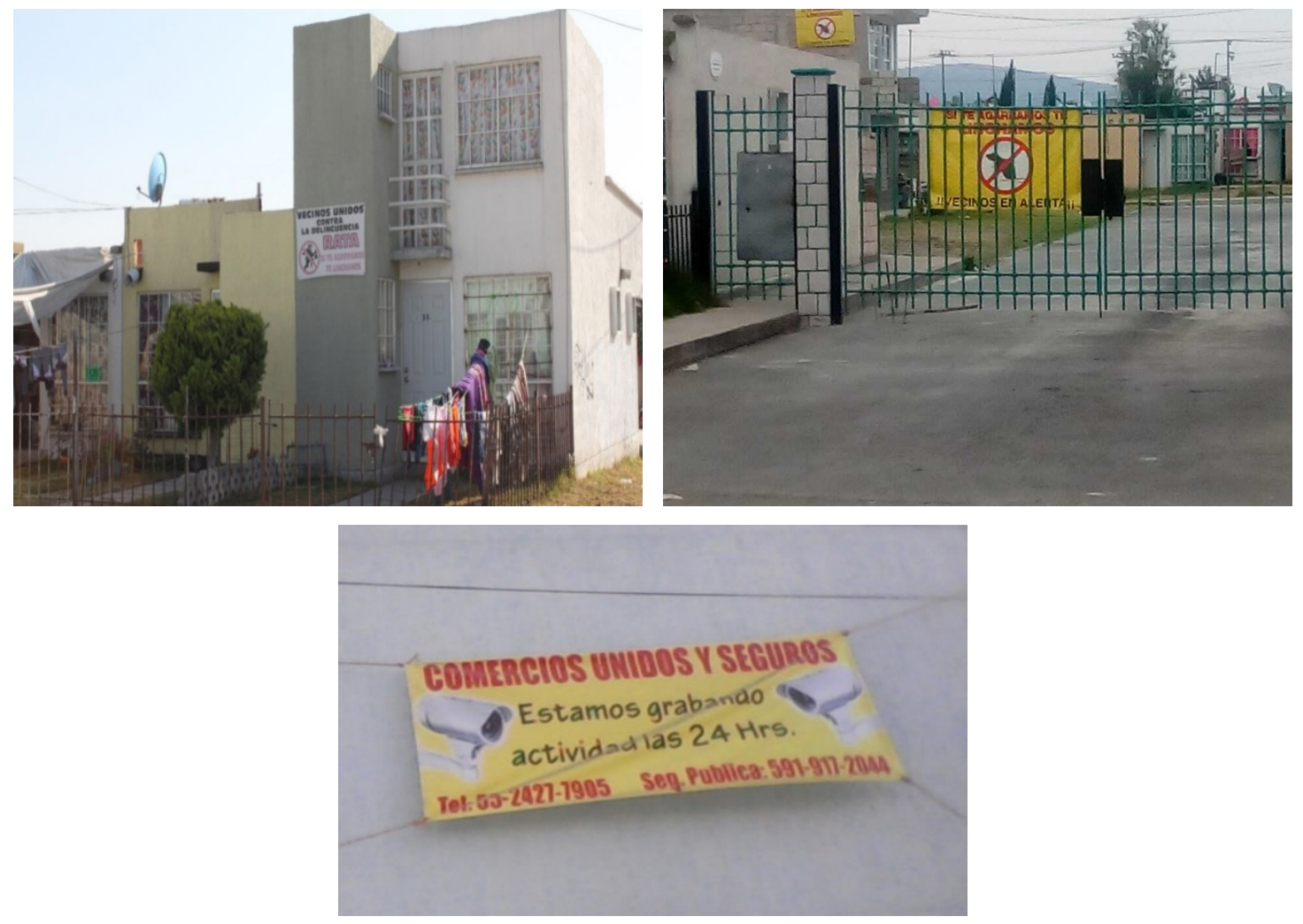

Nota. La manta colgada en la pared de la casa dice lo siguiente: "Vecinos unidos contra la delincuencia. Rata si te agarramos, te linchamos". La manta colgada en la reja dice: "Si te agarramos, te linchamos. Vecinos en alerta". La manta colgada en la parte alta del local de un negocio dice: "Comercios unidos y seguros. Estamos grabando las 24 horas".

de ofensiva y protección a sus familias y su patrimonio, por el abandono del gobierno local y la respuesta limitada de los cuerpos policíacos, que casi siempre llegan tarde cuando ocurre algún delito (Figura 5). Una habitante de ese lugar comenta:

Fue algo que se organizó entre vecinos. Nos cooperamos para mandar a hacer una lona en donde se da aviso (a los delincuentes) de que somos vecinos unidos y estamos vigilando por cualquier situación. A veces, pues sí, es un aviso, no es amenaza, para que el delincuente lo piense un poquito más (E. Gómez, entrevista semiestructurada, 16 de marzo de 2018).

Por lo tanto, aquí se entiende que la percepción social de la inseguridad está estrechamente relacionada con las experiencias cotidianas de los sujetos, sobre lo que hacen, dicen, ven, escuchan y sienten. Es resultado del tiempo que llevan habitando en ese lugar, de lo significativo que ha sido vivir en un espacio precario, violentado y olvidado por las instituciones del Estado (Guerrero Valebenito; 2007; Oehmichen Bazán, 2013) que, en lugar de implementar políticas públicas para combatir y reducir dicha condición de pauperización, la capitalizan de forma clientelar en tiempos electorales.

\section{Narrativas sobre la inseguridad en el Fraccionamiento Villas de la Laguna}

Las narrativas socioespaciales de los sujetos sobre la inseguridad en el Fraccionamiento Villas de la Laguna son el mecanismo por el cual expresan lo que perciben, en la interacción con su entorno inmediato de existencia, con sus familiares, amigos, vecinos o desconocidos. Para ello, usan diferentes dispositivos como son los sentidos, el cuerpo y las tipificaciones o lenguajes que sirven para ubicar y nombrar aquellos espacios que les resultan amenazantes o peligrosos. Por consiguiente, su experiencia percibida y vivida, se nutre de los rumores y de sus desplazamientos diarios sobre el territorio. 
Se encuentra que hay una sensación visual de desagrado y temor hacia determinados lugares del fraccionamiento, por las condiciones precarias de equipamiento urbano en las que se encuentra, como la falta del servicio de luz eléctrica o calles en mal estado. De igual forma, se observa que los rumores juegan un papel central en la formación de este tipo de percepciones, aunque los sujetos no hayan sido víctimas de la delincuencia. Al respecto un habitante comenta:

Hasta atrás en, la última torre (pozo de agua fuera de servicio), ahí es muy inseguro, también donde está el OXXO; no hay luz. Todo lo que es calle de Texcoco y Pátzcuaro no hay nada de luz, es donde ellos agarran (delincuentes) y roban a la gente que pasa por ahí, pero no ves quién te roba, sí es un mototaxista o alguien de la Trini (La Trinidad, fraccionamiento contiguo a nuestra unidad geográfica de estudio) (J. Escobar, entrevista semiestructurada, 15 de diciembre de 2017).

De igual modo, en la vida cotidiana de los habitantes de este lugar es común un tipo de "habla del crimen" (Caldeira, 2007), es decir, los sujetos a diario construyen juicios u opiniones a través de las conversaciones que sostienen con sus cercanos o no, sobre los hechos delictivos y de violencia que ocurren en varios sitios, como en la calle o avenida donde se encuentran sus viviendas. Así lo menciona Joaquín:

Aquí todo se dice (rumora), mi hermano se informa porque tiene su negocio de aguas y platica con la gente sobre las matanzas (asesinatos) que ocurren (J. Escobar, entrevista semiestructurada, 15 de diciembre 2017).

En ese mismo sentido, J. M. Mireles comenta:

Es común oír que ya mataron a alguien en la tienda o que ya volvieron a asaltar en el OXXO, o que pasan dos tipos en las motos pidiendo, aparentemente, cooperación a los negocios, si no los asaltan (J. M. Mireles, entrevista semiestructurada, 5 de diciembre 2017).

Los sujetos interpretan e internalizan el rumor, ante un acto criminal como un asesinato, se generan múltiples versiones.
Dijeron que mataron al abarrotero, pero solo lo mandaron al hospital. Pero lo que me dijeron es que lo mataron, pero pasó unas dos semanas y volvió a su abarrotera, volvió a comprar sus cosas (...) lo que sí le hicieron fue que lo golpearon. Lo mandaron al hospital, fue todo (J. Escobar, entrevista semiestructurada, 15 de diciembre 2017).

Otro relato sobre el asesinato del abarrotero fue el siguiente:

Oímos disparos y la gente empezó a alborotarse, a gritar. Llegaron como tres patrullas, pero los asesinos ya se habían dado a la fuga (huido) (...) uno de nosotros fue a checar y, sí, efectivamente ya estaba un muerto (J. M. Mireles, entrevista semiestructurada, 5 de diciembre 2017).

Es así como en los actos cotidianos del habla (Goffman, 2006) los rumores son una forma de simplificar, nombrar y reproducir las acciones criminales que pueden ser creíbles o no por el otro u otros (Joseph, 1988; Pomerantz y Fehr, 2008; Reumaux, 2009). De igual manera, en los rumores se estigmatizan a ciertos habitantes y los lugares que habitan, en los relatos se da cuenta de la presencia de regiones morales inseguras y peligrosas en ese lugar (Agier, 1996; Park, 1999; Wacquant, 2007; Wacquant, Slater y Borges Pereira, 2014).

Es notorio el estigma hacia determinados grupos sociales como trabajadores informales y personas con algún tipo de adicción. Un habitante comenta lo siguiente:

Un día fui al Aurrera y vi que estaba muy oscuro donde está el OXXO y, pues, en la calle Texcoco todavía había luz y me fui por ahí. La verdad todos los monosos (personas que consumen solventes) de aquí o los que andan en los mototaxis, pasan por ahí, por donde no hay luz, siempre evito todas esas calles, me hacen sentir inseguro (J. Escobar, entrevista semiestructurada, 15 de diciembre de 2018).

Por otra parte, los sonidos que los sujetos escuchan a determinada hora del día, tarde o noche, los interpretan de 
acuerdo con su acervo de conocimiento socioculturalmente construido sobre la inseguridad. En ese sentido, cuando los residentes oyen a cierta distancia un ruido estruendoso, suelen relacionarlo con la detonación de un arma de fuego, que a su vez vinculan con otros hechos como asesinatos, robos o enfrentamientos entre el personal de la policía local o estatal y los posibles delincuentes.

Particularmente en la noche oyes el famoso balazo (...) son varias veces que hemos escuchado que en la noche se oyen balazos a la distancia y, al siguiente día, nos enteramos de que mataron a alguien allá arriba (en otra parte del Fraccionamiento Villas de la Laguna). Al siguiente día varios hablan y te enteras de que mataron al vecino por un asunto de cuentas. Cuando en la noche oyes un balazo, ya al siguiente día los rumores o lo que te dice la gente, te lo confirma. Y como en Villas el lugar es relativamente pequeño hasta el nombre del muerto te dicen (J. M. Mireles, entrevista semiestructurada, 5 de diciembre 2017).

Asimismo, Emma Hernández residente también de ese lugar afirma:

Una vez estábamos en la casa y como a las cinco de la tarde se empezaron a escuchar disparos, según una vecina decía que era gente que está festejando, que está contenta, pero a mí me da pendiente por las balas pérdidas, porque luego mis hijos salen a jugar. Otra vez, escuché, también, que rompieron un vidrio, se había metido el señor ratero a abrir una casa (...) no porque yo lo haya estado viendo, sino que ya después escuché que alguien dijo, que se metieron a robar a la casa del vecino que se va a trabajar, por eso se metieron cuando él no estaba (E. Hernández, entrevista semiestructurada, 20 de diciembre 2017).

En la percepción de los hechos delictivos, tal como se muestra en los testimonios, el uso de los sentidos como el oído o la vista (Simmel, 1986) es fundamental. Por tanto, los sentidos son el eslabón entre el reconocimiento y la interacción de estos sujetos con sus pares y su entorno inmediato.
De tal manera que los residentes de dicho fraccionamiento perciben la inseguridad a través de su cuerpo, el cual parece como una máquina organizada, productora de símbolos y significados, ambos componentes sustanciales de los lenguajes y las experiencias que comunican en su vida cotidiana (Berger \& Luckmann, 2008; Blumer, 1982; Garfinkel, 2006).

El cuerpo es una pieza clave para su movilidad cotidiana en el fraccionamiento o su casa. Al caminar los sujetos se apropian textual y simbólicamente de los espacios que consideran inseguros y los que no, ya sea por efecto de los rumores escuchados o por experiencia propia.

En este caso, la casa es el espacio que se considera más seguro:

mientras a mí no me pase, mi casa está segura (...) estando con mi familia adentro de la casa, ya estoy tranquila y estoy en paz (G. Pérez, entrevista semiestructurada, 20 de diciembre 2017).

En contraparte, la calle es un lugar inseguro:

Estando en mi casa me siento seguro, al estar en la calle me siento más o menos seguro porque no veo, no siento quién viene o con qué viene y, pues, estar en la oscura (sin alumbrado público) también me hace sentir inseguro. Es mejor prevenir donde haya un lugar con luz a un lugar oscuro, porque ahí siempre están los monosos, los ratas (delincuentes) (J. Escobar, entrevista semiestructurada, 15 de diciembre 2017).

Los sujetos al caminar perciben a los lugares como seguros o inseguros y se apropian simbólicamente de dichos espacios por medio del lenguaje (Hoyaux, 2006). Por ejemplo, en sus conversaciones cotidianas es común el uso de palabras o frases como: "dicen que allá", "ahí asaltaron", "en ese lugar consumen drogas", "ahí mataron a un señor”, entre otros.

Dicen que asaltaron una tienda y golpearon al dueño, se tuvo que ir de ahí. Pasas por ahí y está super solito. Por ahí yo pasaba, pero ahora prefiero dar toda la 
vuelta (...) por Laguna de Zurahuen (nombre de calle) aunque ahí también está feo. Ya ni te dan ganas ni de salir (E. Hernández, entrevista semiestructurada, 20 de diciembre 2017).

En otro testimonio se puede leer lo siguiente:

Es que yo siento que la parte más insegura es donde te digo que están las combis (transporte público). Porque primero está el llano, o sea, de ahí te agarran y quién te hace caso ¡nadie! Dos, porque te digo que los (hace referencia a los choferes de las combis) de las combis tienen muchas broncas (problemas entre ellos), siempre llegan y los jinetean (los extorsionan pandilleros y otros grupos del crimen organizado). Entonces, yo sí siento y dónde me he enterado (por rumores) que ha habido más muertes es en ese espacio donde están las combis. Te digo porque cada fin de semana se oyen balazos, dicen que matan y asaltan (P. Cantú, entrevista semiestructurada, 20 de marzo de 2018).

Ante tal situación, los habitantes de este lugar cambian sus rutinas, los lugares por donde transitan y el horario más adecuado para hacerlo. Un habitante comparte su experiencia:

Evito las calles que están oscuras porque sé que son inseguras, mejor vale más mi vida a que me den un navajazo, una bala; no lo vale el dinero. Es lo que yo hago cuando me siento inseguro, paso por una calle que está iluminada (J. Escobar, entrevista semiestructurada, 15 de diciembre 2017).

Algunos espacios son más inseguros que otros, en parte, por las condiciones de deterioro material, abandono y saqueo en las que se encuentran muchas viviendas. Los habitantes creen que estos inmuebles son espacios peligrosos e idóneos para la delincuencia y el consumo de drogas:

Hay muchas casas solas, ahí se meten a drogarse y se escoden los rateros. Ahí (en la periferia del Fraccionamiento Villas de la Laguna) se rumora que mataron a un señor. La verdad desconozco si sea verdad o no (...) muchas veces, cayendo la noche es muy difícil que una señorita, que una mujer, ande por esas calles que están vacías. Les vayan a hacer algo. Pues sí está muy peligroso por ese lado (señala el perímetro del lugar) (R. Godínez, entrevista semiestructurada, 10 de noviembre de 2016).

Los sujetos perciben cotidianamente la inseguridad y han aprehendido a vivir con ello, usan consciente e inconscientemente diversos dispositivos como el cuerpo, los sentidos y el lenguaje, los cuales son herramientas indispensables para interactuar con los otros y, al caminar, conocer su territorio de existencia.

Las formas de percibir la inseguridad son influenciadas por los rumores, el vaivén de los relatos sobre los actos de delincuencia y violencia en este lugar definen qué espacios son más seguros o inseguros, violentos o no violentos. Los sujetos en sus narraciones estigmatizan determinados lugares y aquellos que los habitan, dan cuenta de cómo se apropian simbólicamente de esos espacios y los definen como peligrosos, amenazantes.

\section{Conclusiones}

En la metrópolis de México los fraccionamientos urbanos de reciente creación están formando nuevas periferias, dichos lugares son producto del engarzamiento políticoeconómico entre una débil política estatal de vivienda de interés social y la acción determinante del capital inmobiliario, tal es el caso del Fraccionamiento Villas de la Laguna en el municipio de Zumpango, un espacio destinado para las clases populares.

Los habitantes de este lugar experimentan en su vida cotidiana la concatenación de varias problemáticas, el desempleo, la falta de servicios (salud, educación, agua, drenaje, luz eléctrica, recolección de residuos sólidos, entre otros), el deterioro de las calles y el abandono de las viviendas, así como la violencia e inseguridad que influyen en la interacción social, la subjetividad y las prácticas socioespaciales de dichos sujetos. 
Existe una amplia discusión sobre la inseguridad en la Zona Metropolitana del Valle de México, pero en la literatura reciente son preponderantes aquellos trabajos que problematizan los espacios destinados para las clases medias y altas, y son casi inexistentes las investigaciones sobre las clases populares que se ubican en los otros espacios periféricos, marginados y pobres. Por ello, este texto pretende ser un llamado e invitación a observar y comprender más allá de la realidad inmediata sobre la inseguridad que muestran los datos estadísticos oficiales, los periódicos, la televisión o las redes sociales, incluso sugiere no construir o abordar una realidad desde el confort o el propio estigma de las y los investigadores hacia los lugares y los sujetos que los habitan.

En este artículo se analizó de manera diferente cómo la percepción social de la inseguridad y la apropiación simbólica del espacio son procesos interrelacionados en el devenir cotidiano de estas personas que forman parte del otro gran cinturón de miseria en formación en la metrópolis de México. Se destacó que sus formas de percibir y vivir la inseguridad están relacionadas con los rumores y el caminar. En estas prácticas, el cuerpo, los sentidos y el lenguaje funcionan como dispositivos o herramientas que les permiten desenvolverse de mejor manera en este espacio que definen como inseguro o peligroso.

Finalmente, hemos implementado un aparato teóricometodológico que nos permitió problematizar a detalle cómo los sujetos que habitan este tipo de fraccionamientos perciben la inseguridad y se apropian simbólicamente de su espacio inmediato de existencia. Este acercamiento ofrece otros elementos para la reflexión sobre este tipo de hechos socioterritoriales en las periferias urbanas contemporáneas de México y de las ciudades latinoamericanas.

\section{Referencias bibliográficas}

Agier, M. (1996). Les savoirs urbains de l'anthropologie. Enquête, 4, 35-58. https://doi.org/10.4000/enquete.683

Aguilera Ortega, J. y Corral Fernández, A. (1993). La producción de suelo urbano a través de fraccionamientos en el Estado de México (1946-1992). Universidad Autónoma del Estado de México.

Alliman, A. \& Killias M. (1992). Perceptions et reactions sociales face a la violence: Le sentiment d'insécurité et sa conceptualisatio. Revue Européenne des Sciences Sociales, 30(94), 111-130. jstor.org/stable/40369994? seq=1

Amnistía Internacional (2016). La situación de los derechos humanos en el mundo. https://www.amnesty.org/es/ documents/pol10/2552/2016/es/

Arellano, C. (01 de septiembre 2014). Rehenes de la delincuencia. La Jornada. https://www.jornada.com. mx/2014/09/01/politica/002n1pol

Arriaga Luco, C. y Morales Lazo, N. (2006). Ciudad y seguridad ciudadana en Chile: Revisión del rol de la segregación sobre la exposición al delito en grandes urbes. EURE, 32(9), 37-48. http://dx.doi.org/10.4067/S0250-71612006000300003

Augoyard, J. F. (1979). Pas a pas. Essai sur le cheminement quotidien en milieu urbain. Éditions du Seuil.

Azaola, E. (2012). La violencia de hoy, las violencias de siempre. Desacatos, 40, 13-22. https://doi.org/10.29340/40.253

Azuela, A. (1990). La ciudad, la propiedad privada y el derecho. El Colegio de México.

Barker, A. \& Crawford, A. (2011). Peur du crime et insécurité. Quelque réflexions sur les tendances de la recherche anglo-américaine. Déviance et Société, 1(35), 59-91. https://doi.org/10.3917/ds.351.0059

Berger, P. y Luckmann T. (2008). La construcción social de la realidad. Amorrortu Editores. 
Bergman, M. y Kessler, G. (2008). Vulnerabilidad al delito y sentimiento de inseguridad en Buenos Aires: determinantes y consecuencias. Revista Desarrollo Económico, 190(48), 209-234. https://dialnet.unirioja. es/ejemplar/228912

Blakely, E. J. \& Snyder, G. (1997). Architecture of Fear. Princeton Nan Ellin.

Blumer, H. (1982). El interaccionismo simbólico: perspectiva y método. Hora.

Breetzke, G. D. (2014). Is it Safer behind The Gates? Crime and Gated Communities in South Africa. Journal of Housing and Built Environment, 29(1), pp. 123-139.

Caldeira, T. P. (2007). Ciudad de muros. Gedisa.

Capron, G. (2016). El otro como amenazay la internacionalización de la diferencia en ámbitos residenciales cerrados suburbanos del Área Metropolitana de la Ciudad de México. Sociológica, 31(89), 45-68. http://www.scielo. org. $\mathrm{mx} /$ scielo.php?script=sci_abstract\&pid=S018701732016000300045\&lng=es\&nrm=iso

Capron, G. (2019). Coproducción de la seguridad pública en urbanizaciones cerradas del Valle de México. Nueva Antropología, 41, 10-25. https://www.nuevantropologia. org.mx/index.php/osjdata_na/article/view/20/17

Capron, G. y Esquivel Hernández, M. (2016). El enclave urbano, lógica socioespacial de la periferia urbanizada y sus efectos sobre la segregación residencial y la fragmentación urbana. Cuadernos de Geografía: Revista Colombiana de Geografía, 25(2), 127-150. https://doi. org/10.15446/rcdg.v25n2.54720

Capron, G. y Sánchez, C. (2015). La (in)seguridad en la metrópoli: territorio, segurización y espacio público. Universidad Autónoma Metropolitana, Azcapotzalco.

Carrión, F. (2008). Violencia urbana: un asunto de ciudad. EURE, 103(34), 111-130. http://dx.doi.org/10.4067/ S0250-71612008000300006
Castillo, O. A. y Alejandre, G. (2012). La habitabilidad en la construcción del espacio: el caso de La Trinidad, Zumpango. Quivera, 2, 49-72.

Céline, J. \& Capron, G. (2010). De la gated-community au lotissement géant mexicain: Une version bon marché de la fermeture résidentielle. Cahiers des Amériques latines, 59, 33-35. https://doi.org/10.4000/cal.1091

Chase, J. (2008). Their Space: Security and Service Workers in a Brazilian Gated Community. Geographical Review, 98(4), 476-495. https://doi.org/10.1111/j.1931-0846.2008.tb00313.x

Comisión Coordinadora para el Impulso a la Competitividad del Estado de México (2007). Ciudades del Bicentenario. http://edomexico.gob.mx/sedeco/competitividad/ ppt/CiudadesBicentenario.pdf

Comisión Interamericana de Derechos Humanos (2015). Situación de los derechos humanos en México. http://www. oas.org/es/cidh/informes/pdfs/mexico2016-es.pdf

Coulomb Bosc, R. (2013). Las políticas de vivienda de los estados latinoamericanos. En B. R. Ramírez Velázquez y E. Pradilla Cobos (Eds.), Teorías sobre la ciudad en América Latina. Volumen II (pp. 563-617). Universidad Autónoma Metropolitana-Unidad Xochimilco.

Cruz-Muñoz, F. e Isunza, G. (2017). Construcción del hábitat en la periferia de la Ciudad de México. Estudio de caso en Zumpango. EURE, 129(43), 187-207. https://doi. org/10.4067/s0250-71612017000200009

Cruz Rodríguez, Ma. S. (2000). Periferia y suelo urbano y la Zona Metropolitana de la Ciudad de México. Sociológica, 15(42), 59-90. http://www.redalyc.org/html/3050/305026734004/

Dammert, L. y Bailey, J. (2005). Reforma policial y participación militar en el combate a la delincuencia. Análisis y desafíos para América Latina. Revista Fuerzas Armadas y Sociedad, 1, 133-152.

Davis, M. (2001). Control urbano: la ecología del miedo. Virus Editorial. 
De Certeau, M. (2000). La invención de lo cotidiano. 1 Artes de hacer. Instituto Tecnológico y de Estudios Superiores de Occidente; Universidad Iberoamericana.

Duhau, E. y Giglia, Á. (2004). Espacio público y nuevas centralidades. Dimensión local y urbanidades en las colonias populares de la Ciudad de México. Papeles de Población, 10(41), 167-194. www.scielo.org.mx/scielo. php?pid=S140574252004000300006\&script=sci_arttext

Enríquez Acosta, J. Á. (2007). Entre el miedo y la distinción. El estado actual del fraccionamiento cerrado en las ciudades fronterizas de Tijuana, Nogales y Ciudad Juárez. Estudios Fronterizos, 8(15), 9-19. https://doi. org/10.21670/ref.2007.15.a01

Esquivel, M. T., Flores, R. y Ponce, G. (2006). Dinámica demográfica y espacial de la Zona Metropolitana del Valle de México. En M. S. Cruz Rodríguez (Ed.), Espacios Metropolitanos 2. Población, planeación y políticas de gobierno. Programa Editorial de la Red de Investigación Urbana; Universidad Autónoma Metropolitana, Unidad Azcapotzalco, División de Ciencias Sociales y Humanidades.

Fernández Poncela, A. M. (2012). Psicología de masas, identidad social, epidemias, y rumores: la influenza en México. Sociológica, 76(27), 189-230.www.scielo.org.mx/scielo. php?script=sci_arttext\&pid=S0187-01732012000200006

García Peralta Nieto, B. (2016). La vivienda y el Estado mexicano durante el siglo XX: Un enfoque desde la economía política. UNAM-Instituto de Investigaciones Sociales.

Garfinkel, H. (2006). Estudios en etnometodología. Anthropos Editorial.

Garoscio, A. (2006). Représentation sociales de l'insécurité en milieu urbain. Les Cahiers Internationaux de Psychologie Sociale, 69(1), 33-46. https://doi.org/10.3917/ cips.069.0033

Garza, G. (1985). El proceso de industrialización en la ciudad de México 1821-1970. El Colegio de México.
Garza, G. (1990). El carácter metropolitano de la urbanización en México, 1900-1998. Estudios Demográficos y Urbanos, 1(5), 37-59. https://doi.org/10.24201/edu.v5i1.751

Giglia, A. (2003). Espacio público y espacios cerrados en la Ciudad de México. En P. Ramírez Kuri (Ed.), Espacio público y reconstrucción de ciudadanía (pp. 341-365). Facultad Latinoamericana de Ciencias Sociales; Miguel Ángel Porrúa.

Giménez, G. (1999). Territorio, cultura e identidades. La región sociocultural. Estudios sobre las Culturas Contemporáneas, 5(9), 25-57. http://www.culturascontemporaneas. com/contenidos/region_socio_cultural.pdf

Goffman, E. (2006). La presentación de la persona en la vida cotidiana. Amorrortu Editores.

Gondra Bustinza, J. (2008). Los sentimientos de inseguridad y miedo: el origen de una noción. Revista Catalana de Seguretat Pública, 18, 93-104. https://www.raco.cat/ index.php/RCSP/article/view/130163/179601

Gonzáles Luna, F. (2013). Espacialización de la violencia en las ciudades latinoamericanas: una aproximación teórica. Revista Colombiana de Geografia, 1(22), 169-186. https:// doi.org/10.15446/rcdg.v22n1.36309

Guérin-Pace, F. (2003). Vers une typologie des territoires urbaines de proximité. L'Espace Géographique, 32, 333-344. https://doi.org/10.3917/eg.324.0333

Guerrero Valdebenito, M. R. (2007). Segregación socio-urbana y representaciones sociales en dos comunas de Santiago de Chile. Cultura, Representaciones Sociales, 2(3), 151168. http://www.scielo.org.mx/scielo.php?pid=S2007$\underline{81102007000200007 \& \text { script}=\text { sci_arttext }}$

Guerrien, M. (2004). Transformation et fragmentation des espaces urbaines. Le cas de la zone metropolitaine du bassin de Mexico. L'Espace Géographique, 4(33), 336352. https://doi.org/10.3917/eg.334.0336 
Guerrien, M. (2005). Arquitectura de la inseguridad, percepción del crimen y fragmentación del espacio urbano en la zona metropolitana del valle de México. En P. Fraile, J. Bonastra, G. Rodríguez y C. Arella (Eds.), Paisaje urbano, delito y percepción de la inseguridad: Investigación interdisciplinaria del medio urbano (pp. 93-116). Dykinson.

Gutiérrez Lozano, S. (2008). Vivir la inseguridad en la Ciudad de México. El Cotidiano, 135(21), 18-29. https://www. redalyc.org/pdf/325/32513503.pdf

Hernández, N. (15 de enero de 2018). Aqueja crimen en Edomex. Reforma. https://www.reforma.com/ aplicacioneslibre/preacceso/articulo/default.aspx? rval=1\&urlredirect=https://www.reforma.com/aquejacrimen-en-edomex/ar1299752? referer=--7d6161656 62f3a3a6262623b727a7a7279703b767a783a--

Hoyaux, A. F. (2006). Pragmatique phénoménologique des constructions territoriales et idéologiques dans les discours d'habitants. L'Espace géographique, 35(3), 271-285. https://doi.org/10.3917/eg.353.0271

Husserl, E. (1962). Ideas relativas a una fenomenología pura y una filosofía fenomenológica. Fondo de Cultura Económica.

Imitan, W., Olivera, P. y Beswick, J. (2016). Acceso a la vivienda en tiempos neoliberales: un análisis comparativo de los efectos e impactos de la neoliberalización en las ciudades de Santiago, México y Londres. Revista INVI, 31(88), 163190. https://doi.org/10.4067/s0718-83582016000300006

Instituto Nacional de Estadística y Geografía, INEGI (2010). Censo de Población y Vivienda. Aguascalientes. https:// www.inegi.org.mx/programas/ccpv/2010/

Instituto Nacional de Estadística y Geografía, INEGI (2012). Inventario Nacional de Vivienda. http://www. beta.inegi.org.mx/app/mapa/inv/default.aspx

Instituto Nacional de Estadística y Geografía, INEGI (2018). Encuesta Nacional de Victimización y Percepción sobre Seguridad Pública. Aguascalientes. https://www.inegi. org.mx/programas/envipe/2018/
Jasso López, C. (2013). Percepción de inseguridad en México. Revista Mexicana de Opinión Pública, 15, 13-29. https:// doi.org/10.1016/s1870-7300(13)72319-6

Joseph, I. (1988). El transeúnte y el espacio urbano. Sobre la dispersión y el espacio público. Editorial Gedisa.

Juárez Neri, V. M. (2003). Condiciones de la vivienda en la Zona Metropolitana del Valle de México en el año 2000. Scripta Nova- Revista Electrónica de Geografía y Ciencias Sociales, 7. http://www.raco.cat/index.php/ ScriptaNova/article/view/60242

Kenneth, M. (2014). Nueva política social, viejo contrato social: políticas de vivienda y protesta urbana en la periferia de la Ciudad de México, 1960s-1980s. Historia (Santiago), 1(47), 113-132. http://dx.doi.org/10.4067/ S0717-71942014000100005

Kessler, G. (2011). La extensión de inseguridad en América Latina: Relatos, acciones y políticas en el caso Argentina. Revista Sociología Política Curitiba, 40(19), 83-97.

Kessler, G. (2012). Delito, sentimiento de inseguridad y políticas en la Argentina del siglo XXI. En J. A. Zavaleta Betancourt (Ed.), La inseguridad y la seguridad ciudadana en América Latina (pp. 19-41). CLACSO.

Kessler, G. (2013). Algunas hipótesis sobre la extensión del sentimiento de inseguridad en América Latina. Cuadernos de Antropología Social, 37, 25-47. http://www.scielo. org.ar/scielo.php?script=sci_arttext\&pid=S1850275X2013000100003

Laverentz, A. (2012). Narratives of Crime and Criminals: How Places Construct the Crime Problem. Sociological Forum, 2(27), 348-376.

Le Breton, D. (2002). La sociología del cuerpo. Nueva Visión.

Le Breton, D. (2011). Caminar: un elogio. Un ensayo sobre el placer de caminar. La Cifra Editorial.

Lefebvre, H. (2013). La producción del espacio. Capitán Swing. 
Licona Valencia, E. (2015). La etnografía de los "otros" cercanos: la implicación antropológica en las metrópolis. Graffylia, 20,65-75. http://cmas.siu.buap.mx/portal_pprd/work/ sites/filosofia/resources/PDFContent/1326/006.pdf

Lozano Rivera, C. E. (2012). Etnografía y etnógrafo: percepción y bordes existenciales del trabajo de campo y la etnografía hecha en casa. Antropología Experimental, (12), 77-89. https://revistaselectronicas.ujaen.es/index.php/rae/ article/view/1849

Mainhold, G. (2011). Crimen organizado y seguridad en América Latina. Política Exterior, 25(143), 42-96. https:// dialnet.unirioja.es/servlet/articulo? codigo $=3723228$

Maya Solís, B. (2009). Las consecuencias silenciosas de la política de seguridad pública en México. El Cotidiano, 153, 73-78. http://www.redalyc.org/pdf/325/32515310.pdf

Merchand, M. (2016). Estado, vivienda de interés social e inmobiliarias en México. Cuadernos de Vivienda y Urbanismo, 10(19), 6-21. https://doi.org/10.11144/javeriana.cvu10-19.evis

Merleau-Ponty, M. (1994). Fenomenología de la percepción. Ediciones Península.

Moloeznik, M. (2012). Seguridad ciudadana (hacia una radiografía de la seguridad subjetiva en Guadalajara). Ciencia Jurídica, 1(2), 83-106. https://doi.org/10.15174/ cj.v1i2.65

Moloeznik, M. P. y Suárez de Garay, M. E. (2012). El proceso de militarización de la seguridad pública en México (2006-2012). Frontera Norte, 24(48), 121-144. http://www.scielo.org.mx/scielo.php?script=sci_ arttext\&pid=S0187-73722012000200005

Montero, J. C. (2012). Las estrategias contra el crimen organizado en México un análisis del diseño de la política pública. Perfiles Latinoamericanos, 39(20), 7-30. http://perfilesla.flacso.edu.mx/index.php/perfilesla/ article/view/115
Observatorio Nacional Ciudadano de Seguridad, Justicia y Legalidad (2016). Incidencia de los delitos de alto impacto en México 2016. http://onc.org.mx/tag/delitosde-alto-impacto/

Oehmichen Bazán, C. (2013). La "violencia de siempre": Representaciones de la violencia delincuencial en un barrio popular de la Ciudad de México. Anales de Antropología, 47(1), 243-262. https://doi.org/10.1016/ s0185-1225(13)71013-0

ONU-Habitat (2018). Informe final municipal. Zumpango México, México. Índice básico de las ciudades prósperas. INFONAVIT; Secretaría de Desarrollo Agrario. Territorial y Urbano; ONU/Habitat. http://70.35.196.242/onuhabitatmexico/ cpi/2015/15120_Zumpango.pdf

Park, R. (1999). La ciudad y otros ensayos de ecología humana. Ediciones del Serbal.

Pasters W. y Castillo Berthier, H. (2007). Violencia e inseguridad en la ciudad de México: entre la fragmentación y la politización. Foro Internacional, 47(3), 577-615. https:// www.redalyc.org/articulo.oa? $\mathrm{id}=59911150005$

Pirez, P. (2014). La mercantilización de la urbanización. Apropósito de los "conjuntos urbanos en México. Estudios Demográficos y Urbanos, 29(3), 481-512. https://doi. org/10.24201/edu.v29i3.1469

Pomerantz, A. y Fehr, B. (2008). Análisis de la conversación: un enfoque del estudio de la acción social como prácticas de producción de sentido. En T. Van Dijk (Ed.), El discurso como interacción social (pp. 67-101). Editorial Gedisa.

Pradilla Cobos, E. (2016). Zona Metropolitana del valle de México: neoliberalismo y contradicciones urbanas. Sociologías, 18(42), 54-89. https://doi.org/10.1590/15174522018004203

Reumaux, F. (2009). Acerca de la definición del rumor y sus significados. Revista de Comunicación y Política, 23, 103-130. http://studylib.es/doc/6712594/acerca-dela-definici\%C3\%B3n-del-rumor-y-sus-significadoss 
Rouquette, M. L. (2006). Théorie des rumeurs et théorie des problémes. Diógenes, 213(1), 46-53. https://doi. org/10.3917/dio.213.0046

Sanín Naranjo, P. (2012). ¿De la ciudad abierta a la ciudad cerrada? configuraciones socio espaciales en el barrio El Poblado, Medellín. Territorios, (23), 123-142. https:// revistas.urosario.edu.co/index.php/territorios/article/ view/1404

Schteingart, M. (2001). Los productores del espacio habitable. Estado, empresa y sociedad en la Ciudad de México. El Colegio de México.

Schütz, A. (1995). El problema de la realidad social. Amorrortu Editores.

Secretaría de Desarrollo Urbano y Metropolitano (2017). Autorizaciones de conjuntos urbanos 1999-2017. http:// seduym.edomex.gob.mx/autorizaciones

Secretaría de Gobernación y Secretariado Ejecutivo del Sistema Nacional de Seguridad Pública, SNSP (2017). Incidencia municipal 2011-2017. http://secretariadoejecutivo. gob.mx/incidencia-delictiva/incidencia-delictivadatos-abiertos.php

Secretaría de Gobernación y Secretariado Ejecutivo del Sistema Nacional de Seguridad Pública, SNSP (2018). Cifras de homicidio doloso, secuestro, extorsión y robo de vehículos 1997-2017. http://secretariadoejecutivo.gob.mx/ incidencia-delictiva/incidencia-delictiva-fuero-comun.php

Simmel, G. (1986). Sociología 2. Estudios sobre las formas de socialización. Alianza Editorial.

Taylor, S. y Bogdan, R. (1987). Introducción a los métodos cualitativos de investigación. La búsqueda de significados. Ediciones Paidós Ibérica.

Valenzuela-Aguilera, A. (2016). Topología del miedo: impactosen la percepción espacial de la inseguridad en América Latina. Revista Latinoamericana de Estudios de Seguridad, (19), 149-161. https://doi.org/10.17141/urvio.19.2016.2411
Wacquant, L. (2004). Las cárceles de la miseria. Manantial.

Wacquant, L. (2006). Entre las cuerdas. Cuadernos de un aprendiz de boxeador. Siglo XXI Editores Argentina.

Wacquant, L. (2007). Los condenados de la ciudad. Gueto, periferias y Estado. Siglo XXI Editores Argentina.

Wacquant, L, Slater, T. y Borges Pereira, V. (2014). Estigmatización territorial en acción. Revista INVI, 29(82), 219-240. https:// doi.org/10.4067/s0718-83582014000300008

Ward, P. (2004). México megaciudad: Desarrollo y política 1970-2002. El Colegio Mexiquense/ Miguel Ángel Porrúa.

Widner, É., Languin, N., Pattaroni, L., Kellerhals, J., \& Robert, C. (2004). Du sentiment $d$ 'insécurité aux répresentations de la délinquance. Déviance et société, 28(2), 141-157. https://doi.org/10.3917/ds.282.0141

Zamorano, C. (2019a) ¿Quétan pública es la seguridad pública en México? Revista Mexicana de Sociología, 81(3), 479-507. http:// dx.doi.org/10.22201/iis.01882503p.2019.3.57918

Zamorano, C. (2019b). Segurización, gentrificación y Airbnb. Nueva Antropología, 41, 26-48. https://www. nuevantropologia.org.mx/index.php/osjdata_na/ article/view/21/18

Zamorano, C. \& Capron, G. (2013). Privatization of Security and the Production of Space in Mexico City: Challenges for Urban Planning. International Journal of E-Planning Research,2(4). https://doi.org/10.4018/ijepr.2013100105

Zauberman, R., Robert, P., Névanen, S., \& Bon, D. (2013). Victimation et insécurité en Île-de-France. Revue Française de Sociologie, 54(1), 111-153. https://doi.org/10.3917/ rfs.541.0111

Zires, M. (1994). Las dimensiones del rumor: oral, colectiva y anónima, presentado en el II Foro departamental de educación y comunicación. ITESO, Universidad Jesuita de Guadalajara. http://www.lacult.unesco.org/docc/ oralidad_08_23-29-las-dimensiones-del-rumor.pdf 
Zires, M. (1995). La dimensión cultural del rumor. De lo verdadero a los diferentes regímenes de verosimilitud. Comunicación y Sociedad, (24), 155-176. http://www. publicaciones.cucsh.udg.mx/pperiod/comsoc/ pdf/24_1995/155-176.pdf

\section{Entrevistas realizadas}

Cantú, P. (20 de marzo de 2018). Entrevista semiestructurada. Zumpango de Ocampo.

Escobar, J. (15 de diciembre de 2017). Entrevista semiestructurada. Zumpango de Ocampo.

Godínez. R. (10 de noviembre de 2016). Entrevista semiestructurada. Zumpango de Ocampo.

Gómez, E. (16 de marzo de 2018). Entrevista semiestructurada. Zumpango de Ocampo.

Hernández, E. (20 de diciembre de 2017). Entrevista semiestructurada. Zumpango de Ocampo.

López, B. (13 de diciembre de 2017). Entrevista semiestructurada. Zumpango de Ocampo.

Mireles, J. M. (05 de diciembre de 2017). Entrevista semiestructurada. Zumpango de Ocampo.

Pérez, G. (20 de diciembre de 2017). Entrevista semiestructurada. Zumpango de Ocampo. 